\title{
Role of alpha-lipoic acid in the management of anemia in patients with chronic renal failure undergoing hemodialysis
}

This article was published in the following Dove Press journal: International Journal of Nephrology and Renovascular Disease 26 August 2013

Number of times this article has been viewed

\author{
Gehad A El-Nakib' \\ Tarek M Mostafa ${ }^{2}$ \\ Tarek M Abbas ${ }^{4}$ \\ Mamdouh M El-Shishtawy \\ Mokhtar M Mabrouk ${ }^{2}$ \\ Mohammed A Sobh ${ }^{4}$ \\ 'Mansoura University Hospitals, \\ Mansoura, Egypt; ${ }^{2}$ Faculty of Pharmacy, \\ Tanta University, Tanta, Egypt; \\ ${ }^{3}$ Faculty of Pharmacy, Mansoura \\ University, Mansoura, Egypt; ${ }^{4}$ Urology \\ and Nephrology Centre, Faculty \\ of Medicine, Mansoura University, \\ Mansoura, Egypt
}

Introduction: Anemia associated with chronic kidney disease is a serious complication necessitating expenditure of huge medical efforts and resources. This study investigates the role of alpha-lipoic acid (ALA) in end stage renal disease patients undergoing hemodialysis. By the virtue of its antioxidative effects, ALA is expected to act as an erythropoietin (EPO) adjuvant, and also has extended beneficial effects on endothelial dysfunction.

Methods: Forty-four patients undergoing hemodialysis and receiving EPO were randomized into two groups: the first group received ALA $600 \mathrm{mg}$ once daily for 3 months; while the other group represented the control group. Parameters measured at baseline and at end of study were hemoglobin, EPO doses, EPO resistance index (ERI), iron store indices, malondialdehyde, oxidized low-density lipoprotein (ox-LDL), interleukin-6 (IL-6), tumor necrosis factor- $\alpha$ (TNF- $\alpha$ ), and asymmetric dimethylarginine (ADMA), as well as routine laboratory follow-up.

Results: EPO doses and ERI were significantly decreased in the treatment group, while they did not change in the control group. Hemoglobin, iron store indices, malondialdehyde, oxidized ox-LDL, IL-6, TNF- $\alpha$, and ADMA were similar in both treatment and control groups at baseline, and did not change by the end of study period. Likewise, routine laboratory measures were not affected by the treatment.

Conclusion: ALA could be used in hemodialysis patients to reduce requirements for EPO. However, larger and longer term studies are required to clarify the exact role of ALA in hemodialysis as well as in pre-hemodialysis patients.

Keywords: alpha-lipoic acid, anemia, asymmetric dimethylarginine, erythropoietin, hemodialysis, oxidative stress

\section{Introduction}

Anemia is a universal condition of end stage renal disease that is associated with poor outcome; it demands devoting a remarkable amount of resources and continuous effort to attain and maintain hemoglobin within guideline targets. Correction of anemia impacts essential outcomes such as quality of life, ${ }^{1}$ cardiovascular function, ${ }^{2,3}$ and survival. ${ }^{4}$ Erythropoietin (EPO) therapy has become the cornerstone of standard care when treating anemia in chronic kidney disease. However, implementation of anemia management guidelines ${ }^{5,6}$ in real practice is hardly ever achieved, due mainly to complexity of complications accompanying end stage renal disease. This is noted particularly in developing countries, where economics greatly impact healthcare decisions. Another serious issue is the suggested association between administration of large EPO doses and an increased risk of cardiovascular complications and/or mortality. ${ }^{7,8}$

Reports studying EPO adjuvants being continuously compiled and published; however, no conclusive role for EPO adjuvants has until now been stated. Antioxidants
Correspondence: Gehad A El-Nakib

Mansoura University Staff

Accommodation, Building no I,

Jehan Street,

Mansoura, Egypt

Tel +20 1098755250

Fax +200502244852

Email gehadelnakeeb@yahoo.com
International Journal of Nephrology and Renovascular Disease 2013:6 I6I-I68

(c) (i) (5) 2013 El-Nakib et al. This work is published by Dove Medical Press Ltd, and licensed under Creative Commons Attribution - Non Commercial (unported, v3.0)

Dovepress

http://dx.doi.org/10.2147/IJNRD.S49066 
have been attracting attention by virtue of their role in targeting oxidative stress, acting both as effector and consequence, and linking various risk factors of anemia and subsequent cardiovascular risk; additionally, they are of interest due to their leading role in EPO hyporesponsiveness. Antioxidants like Vitamin E, supplied orally or bound to the hemodialysis membrane, have been studied extensively; these studies have produced conflicting results on EPO responsiveness and dose reduction, as well as on other parameters such as oxidativeinflammatory markers and cardiovascular outcome. ${ }^{9-11}$ Conflicting results have also been mentioned for other antioxidants such as ascorbic acid, ${ }^{12,13} \mathrm{~N}$-acetylcysteine, ${ }^{14,15}$ and antioxidant combinations. ${ }^{16}$ In addition, negative side effects have increased concern about their use, such as oxalosis with ascorbic acid, ${ }^{17}$ toxicity, or even increased mortality with vitamin E. ${ }^{18}$ In spite of its benefits, the impracticalities of electrolyzed-reduced water use has prevented its widespread use. $^{19}$

Alpha-lipoic acid (ALA) is a naturally occurring compound that is de novo synthesized in mitochondria and is an essential cofactor for certain dehydrogenase enzymes during mitochondrial energy metabolism. It acts as a potent antioxidant through multiple mechanisms. It scavenges reactive oxygen and nitrogen species, regenerates other antioxidants such as ascorbic acid, glutathione, alpha-tocopherol and coenzyme $\mathrm{Q}_{10}$, and chelates reactive free metal ions. Regarding its safety, it has been reported that doses of up to $1800-2400 \mathrm{mg} /$ day can be tolerated safely in humans without reported toxicity or significant adverse side effects. ${ }^{20,21}$ Growing evidence has demonstrated a nephroprotective role for ALA; it improved histological lesions, ameliorated renal oxidative stress and inflammatory markers, and lowered the increase in serum creatinine and urea in rats induced by different insults. ${ }^{22-25}$

The present study investigates the role of ALA as an EPO adjuvant in end stage renal disease patients undergoing hemodialysis. It also examines its antioxidative, antiinflammatory effects, and its role in endothelial dysfunction. To our knowledge, this is the first study investigating ALA effect on anemia management.

\section{Patient and methods}

This study was conducted at the outpatient dialysis unit of Mansoura University's Urology and Nephrology Centre. Forty-four end stage renal disease patients undergoing maintenance hemodialysis were randomly assigned to two groups of 22 patients each. Twenty-two patients comprised the treatment group and were given ALA (Thiotacid; EVA
Pharma, Cairo, Egypt) 600 mg once daily (after hemodialysis sessions in days of dialysis), whereas the other 22 patients served as the control group. The clinical study was in accordance with the principles of the Declaration of Helsinki. It was approved by Mansoura University's Medical Research Ethics Committee, and the patients gave their consent after being informed about the nature of the study.

Patients were anemic, were administered alpha recombinant human EPO (Epoetin; Sedico, Cairo, Egypt) as scheduled according to their needs, underwent hemodialysis three times weekly, and had adequate hemodialysis for at least 6 months using bicarbonate-based dialysate and polysulfone membrane dialyzers. Patients with symptoms of active infections or acute inflammation, malignancy, active Hepatitis $C$ virus infection (HCV) (as evidenced by elevated liver enzymes), or a history of recent surgery or significant blood loss were excluded. Complete disease and drug histories and other relevant biodata were taken for all the patients. A summary of baseline data is presented in Table 1.

Blood samples used for determination of study parameters were collected during appointments that were scheduled by the dialysis unit for routine patients' examinations. They were collected prior to the second session of the week at the start and at the end of the 3-month study period. Non lipemic or hemolytic samples were immediately placed on ice. Plasma samples were mixed with (ethylenediaminetetraacetic acid) EDTA, centrifuged at $1000 \mathrm{~g}$ for 15 minutes, and aliquots were stored at $-80^{\circ} \mathrm{C}$ till assay. They were used for determination of asymmetric dimethylarginine (ADMA), interleukin-6 (IL-6), tumor necrosis factor alpha (TNF- $\alpha$ ), and oxidized low-density lipoprotein (ox-LDL). Serum samples were also stored at $-80^{\circ} \mathrm{C}$ for determination of malondialdehyde (MDA) and ferritin; other serum samples were used for the remaining assays and kept at $2^{\circ} \mathrm{C}-8^{\circ} \mathrm{C}$ and used instantly.

Table I Baseline characteristics of the treatment and control groups

\begin{tabular}{lll}
\hline & $\begin{array}{l}\text { Treatment group } \\
(\mathbf{n}=\mathbf{2 2})\end{array}$ & $\begin{array}{l}\text { Control group } \\
(\mathbf{n}=\mathbf{2 2})\end{array}$ \\
\hline Age (years) & $49.1 \pm 16.2$ & $46.2 \pm 14.4$ \\
Sex (female/male) & $10 / 12$ & $10 / 12$ \\
Smokers & 3 & 3 \\
Patients with diabetes mellitus & 7 & 3 \\
Patients with HCV & 16 & 16 \\
Time on dialysis (year) & $6.6 \pm 4.3$ & $8.8 \pm 6.3$ \\
iPTH $(\mathrm{pg} / \mathrm{mL})$ & $647.9 \pm 583.3$ & $464.5 \pm 505.8$ \\
\hline
\end{tabular}

Note: Values expressed as mean \pm SD.

Abbreviations: HCV, Hepatitis C virus; iPTH, intact parathyroid hormone; $\mathrm{SD}$, standard deviation. 
ADMA was determined by the use of enzyme linked immunoassays (Immunodiagnostik AG, Bensheim, Germany) according to manufacturer directions; the same was done for ox-LDL (Immunodiagnostik AG), IL-6 (R\&D Systems, Minneapolis, MN, USA), TNF- $\alpha$ (R\&D Systems, USA), and ferritin (Monobind Inc, Lake Forest, CA, USA). A Biotek ELx800 (BioTek Instruments, Inc, Winooski, VT, USA) was used to read ELISA assays. MDA was determined using the thiobarbituric acid reactive substances method; $0.5 \mathrm{~mL}$ of serum was mixed with $2.5 \mathrm{~mL} 20 \%$ trichloroacetic acid and $1 \mathrm{~mL}$ of $0.67 \%$ thiobarbituric acid. The mixture was incubated in a boiling water bath for 45 minutes, followed by cooling in tap water. Samples were mixed, shaken with $4 \mathrm{~mL}$ butanol and centrifuged to facilitate separation of layers. The upper red-colored butanol phase was separated and quantified spectrophotometrically at $535 \mathrm{~nm}$. Malonaldehyde bis(diethylacetal) (1,1,3,3 tetraethoxypropane) was used as standard (all reagents supplied by Sigma-Aldrich [St Louis, MO, USA]). ${ }^{26}$ Hemoglobin concentration was determined using Sysmex KX-21N hematology analyzer (Sysmex Corporation, Kobe, Japan). The EPO dose was estimated as the weekly dose requirements per patient, and EPO resistance index (ERI) was calculated as the ratio of the dose adjusted for body weight after a hemodialysis session, to hemoglobin concentration. ${ }^{27}$ Iron was determined by the chromazurol B method. Transferrin saturation (TSAT\%) was calculated by dividing the serum iron concentration by the total iron binding capacity and multiplying the result by 100 , to obtain a percentage. Other laboratory parameters were measured via their routine methods.

\section{Statistics}

The data was presented as mean \pm standard deviation (SD). The Kolmogorov-Smirnov test was used to test normality of data distribution. Groups at baseline were compared using Student's $t$-test or Mann-Whitney $U$-test as appropriate. Paired $t$-test or Wilcoxon signed-ranks test was used to compare values within each group at baseline and at the end of the 3-month study. Chi-square test was used for comparing categorical values. Univariate analysis using Spearman's correlation test and analysis of covariance were performed to test possible baseline factors that could confound ERI results. Statistical Package for Social Sciences (SPSS version 20; IBM Corporation, Armonk, NY, USA) for Windows was used. $P<0.05$ was considered statistically significant.

\section{Results}

Nine patients were withdrawn from the original randomized sample of 53 patients; four patients from the treatment group and five from the control group. Two patients were in the treatment group and withdrawn due to gastrointestinal side effects, one patient suffered from hemorrhoids, and another patient underwent surgery to fix a fracture in her lumbar spine; additionally, two patients received transplants and three others were hospitalized for recurrent infections. Treatment group patients who completed the assigned treatment periods displayed $85 \%$ compliance.

There was no significant difference between the treatment and control groups regarding baseline characteristics (Table 1) and laboratory parameters. Additionally, there were no changes in laboratory parameters by the end of the study in both treatment and control groups (Table 2). The changes in hemoglobin concentration, EPO doses, ERI, and iron indices are summarized in Table 3. There was no significant difference in the baseline values between the treatment and control groups. There were significant changes in the treatment group by the end of the study in EPO doses and ERI, whereas there were no significant changes in these values for the control group. There was no significant change between baseline and end of study in both treatment and control groups for hemoglobin concentration, serum iron, total iron binding capacity (TIBC), TSAT\%, and ferritin.

The changes in MDA, ox-LDL, IL-6, TNF- $\alpha$, and ADMA are summarized in Table 4 . There was no significant

Table 2 Changes in laboratory markers in treatment and control groups

\begin{tabular}{|c|c|c|c|c|}
\hline & $\begin{array}{l}\text { Treatment group, } \\
\text { baseline }\end{array}$ & $\begin{array}{l}\text { End of the study } \\
(n=22)\end{array}$ & $\begin{array}{l}\text { Control group, } \\
\text { baseline }\end{array}$ & $\begin{array}{l}\text { End of the study } \\
(n=22)\end{array}$ \\
\hline Serum phosphorous (mg/dL) & $5.0 \pm 1.2$ & $5.2 \pm 1.2$ & $5.3 \pm 2.0$ & $5.3 \pm 1.7$ \\
\hline Serum calcium (mg/dL) & $9.4 \pm 0.6$ & $9.4 \pm 0.8$ & $9.5 \pm 0.6$ & $9.2 \pm 0.7$ \\
\hline Serum albumin $(g / d L)$ & $4.2 \pm 0.6$ & $4.4 \pm 0.4$ & $4.6 \pm 0.9$ & $4.5 \pm 0.4$ \\
\hline Serum creatinine $(\mathrm{mg} / \mathrm{dL})$ & $9.8 \pm 2.4$ & $8.9 \pm 2.7$ & $10.2 \pm 2.6$ & $9.2 \pm 2.6$ \\
\hline Serum blood urea nitrogen $(\mathrm{mg} / \mathrm{dL})$ & $65.97 \pm 13.43$ & $60.36 \pm 10.21$ & $74.38 \pm 15.39$ & $67.51 \pm 11.10$ \\
\hline $\mathrm{Kt} / \mathrm{V}$ & $1.4 \pm 0.2$ & $\mathrm{I} .5 \pm 0.2$ & $1.4 \pm 0.3$ & $1.4 \pm 0.3$ \\
\hline
\end{tabular}

Note: Values expressed as mean \pm SD.

Abbreviation: SD, standard deviation. 
Table 3 Changes in anemia control measures in treatment and control groups

\begin{tabular}{|c|c|c|c|c|}
\hline & $\begin{array}{l}\text { Treatment group, } \\
\text { baseline }\end{array}$ & $\begin{array}{l}\text { End of the study } \\
(n=22)\end{array}$ & $\begin{array}{l}\text { Control group, } \\
\text { baseline }\end{array}$ & $\begin{array}{l}\text { End of the study } \\
(n=22)\end{array}$ \\
\hline $\mathrm{Hb}$ concentration $(\mathrm{g} / \mathrm{dL})$ & $10.85 \pm 1.31$ & $11.25 \pm 1.1$ & $11.05 \pm 0.74$ & $11.43 \pm 0.9$ \\
\hline Erythropoietin doses (IU/week) & $6363.64 \pm 3244.7 \mid$ & $5000.00^{a} \pm 2943.92$ & $5727.27 \pm 3224.63$ & $4681.82 \pm 3045.47$ \\
\hline $\begin{array}{l}\text { Erythropoietin resistance index } \\
\text { (IU/kg per week per g/dL) }\end{array}$ & $9.93 \pm 7.35$ & $7.46^{\mathrm{a}} \pm 5.59$ & $8.23 \pm 4.84$ & $6.62 \pm 4.31$ \\
\hline Serum iron $(\mu g / d L)$ & $76.09 \pm 17.15$ & $78.02 \pm 34.65$ & $88.38 \pm 44.78$ & $86.75 \pm 32.64$ \\
\hline Total iron binding capacity $(\mathrm{TIBC})(\mu \mathrm{g} / \mathrm{dL})$ & $324.2 \pm 107.9$ & $280.5 \pm 117.7$ & $325.9 \pm 88.6$ & $311.1 \pm 112.0$ \\
\hline Transferrin saturation (TSAT) (\%) & $26.53 \pm 11.87$ & $29.87 \pm 11.34$ & $27.54 \pm 10.59$ & $30.02 \pm 12.29$ \\
\hline Ferritin $(\mathrm{ng} / \mathrm{mL})$ & $563.60 \pm 351.96$ & $536.64 \pm 310.16$ & $706.46 \pm 451.30$ & $641.05 \pm 393.06$ \\
\hline
\end{tabular}

Notes: Values expressed as mean \pm SD. ${ }^{a} P<0.05$ compared with baseline.

Abbreviations: Hb, hemoglobin; IU, international units; TIBC, total iron binding capacity; TSAT, transferrin saturation; SD, standard deviation.

difference in the baseline parameters between the treatment and control groups. There was no significant change between baseline and end of study in both treatment and control groups in MDA, ox-LDL, IL-6, TNF- $\alpha$, and ADMA.

An analysis for a number of parameters was done for the sub-group of patients with no HCV (12 patients, six in each group). The findings of these selected parameters were that there was no significant difference in baseline parameters between the treatment and control groups. The change in hemoglobin concentration by the end of the study was not significant in both treatment and control groups, from $10.58 \pm 1.26$ to $11.43 \pm 0.91 \mathrm{~g} / \mathrm{dL}$ and $11.08 \pm 0.78$ to $11.27 \pm 1.11 \mathrm{~g} / \mathrm{dL}$, respectively. The changes in EPO doses and ERI in the treated group were from $7000 \pm 3033.15$ to $5000 \pm 4335.9 \mathrm{IU} /$ week $(P=0.06)$ and $11.32 \pm 8.49$ to $7.45 \pm 7.48(P<0.05)$, respectively. In contrast, the changes in EPO doses and ERI in the control group were not significant $(6000 \pm 4000$ to $5000 \pm 3033.15 \mathrm{IU} /$ week and $9.67 \pm 7.71$ to $7.64 \pm 5.34 \mathrm{IU} / \mathrm{kg}$ per week per $\mathrm{g} / \mathrm{dL}$, respectively).

Univariate analysis revealed no correlation between ERI results and age, sex, smoking status, time on dialysis, intact parathyroid hormone (iPTH) values, presence of diabetes mellitus (DM), presence of $\mathrm{HCV}$, and $\mathrm{Kt} / \mathrm{V}$. Only baseline ERI values were correlated with ERI results $(r=0.79$,
$P<0.001)$. Analysis of covariance found no effect for all these covariates.

\section{Discussion}

The present study showed no effects of ALA either on markers of oxidative stress MDA and ox-LDL, or inflammatory markers IL- 6 and TNF- $\alpha$. This was in line with a previous study in which ALA did not affect the inflammatory marker high-sensitivity C-reactive protein (HsCRP), nor did it reduce ox-LDL in hemodialysis patients. ${ }^{28}$

Lack of measurable effect in hemodialysis patients may be attributed to the fact that ALA acts indirectly to augment other endogenous antioxidants; it improves levels of ascorbic acid, glutathione, alpha-tocopherol, and coenzyme $\mathrm{Q}_{10}$, enhancing uptake from the blood, by inducing their synthesis, or by regenerating the reduced form. ${ }^{20,21}$ Hemodialysis is a case of excessively depleted antioxidant status, limiting ALA's ability to perform its complete antioxidative role; in line with this is the suggestion raised in the SPACE study - one of the very few studies with positive effect upon oral administration of vitamin $\mathrm{E}$ in hemodialysis patients - that this positive effect may be due to the coadministration of ascorbic acid, which is capable of maintaining vitamin $\mathrm{E}$ in a reduced state. ${ }^{10}$

The relatively small sample size of the study may hinder beneficial effects in this complicated population; the study

Table 4 Changes in biochemical parameters in treatment and control groups

\begin{tabular}{|c|c|c|c|c|}
\hline & $\begin{array}{l}\text { Treatment group, } \\
\text { baseline }\end{array}$ & $\begin{array}{l}\text { End of the study } \\
(n=22)\end{array}$ & $\begin{array}{l}\text { Control group, } \\
\text { baseline }\end{array}$ & $\begin{array}{l}\text { End of the study } \\
(n=22)\end{array}$ \\
\hline Malondialdehyde $(\mu \mathrm{M})$ & $5.55 \pm 2.01$ & $5.61 \pm 1.55$ & $5.09 \pm 1.98$ & $5.48 \pm 1.63$ \\
\hline Oxidized LDL (ng/mL) & $163.17 \pm 83.10$ & $162.34 \pm 82.80$ & $148.86 \pm 85.55$ & $135.18 \pm 99.34$ \\
\hline Interleukin-6 (pg/mL) & $27.68 \pm 15.24$ & $24.83 \pm 15.74$ & $23.07 \pm 19.49$ & $23.38 \pm 18.87$ \\
\hline Transforming growth factor- $\alpha(\mathrm{pg} / \mathrm{mL})$ & $17.40 \pm 7.74$ & $19.00 \pm 7.62$ & $|5.5| \pm 7.98$ & $17.64 \pm 7.11$ \\
\hline Asymmetric dimethylarginine $(\mu \mathrm{M})$ & $0.592 \pm 0.258$ & $0.642 \pm 0.353$ & $0.609 \pm 0.255$ & $0.681 \pm 0.302$ \\
\hline
\end{tabular}

Note: Values expressed as mean $\pm \mathrm{SD}$.

Abbreviations: LDL, low-density lipoprotein; SD, standard deviation. 
group had multiple different confounding conditions, including smoking, inability to rule out low/high hemoglobin or iron deficiency/overload in the patients at all the time points, and comorbidities such as DM and HCV. A large-scale study could reveal beneficial differences or at least allow controlling for some of these confounders.

One of the most important nontraditional cardiovascular risk factors that explains the high prevalence of cardiovascular complications in patients with chronic renal failure is elevated ADMA. ADMA is the one of the most endogenous inhibitors of nitric oxide synthase (NOS), which produces nitric oxide (NO), thus resulting in endothelial complications. ADMA is not only an active mediator of various cardiovascular complications, ${ }^{29,30}$ it has also been found to predict progressive deterioration of renal function and cardiovascular events in different stages of chronic kidney disease. ${ }^{31,32}$

In cultured endothelial cells, ALA decreased ADMA concentration; it enhances activity of the ADMA-metabolizing enzyme dimethylarginine dimethylaminohydrolase (DDHA) and gene expression. ${ }^{33}$ However, in the present study ALA did not exert an effect on ADMA. This contrasts with other studies of type $2 \mathrm{DM}$ patients ${ }^{34}$ and hemodialysis patients. ${ }^{28}$ Patients in these studies were all diabetics, whereas in the present study only a segment of the study population were diabetics. ALA may act selectively on those patients through antidiabetic mechanisms. ALA mimics insulin-induced glucose handling at the cellular level..$^{35}$ It improves glycemic control in type 2 diabetic patients..$^{36}$ This may be why ALA has enhanced efficacy in a wide array of clinical effects in the diabetes field. In diabetic rat kidney, ALA attenuated albuminuria, glomerulosclerosis, and tubulointerstitial fibrosis, and lowered renal expression of transforming growth factor- $\beta 1$ (TGF- $\beta 1$ ) and inducible NOS (iNOS). ${ }^{24,25}$ It attenuated markers of oxidative stress and inflammation in patients with diabetic overt nephropathy. ${ }^{37}$ It improved endothelial dysfunction in subjects with impaired fasting glucose ${ }^{38}$ and in patients with type 2 diabetes, ${ }^{39}$ and preserved their renal function by inhibiting progressive increase of urinary albumin excretion. ${ }^{40} \mathrm{ALA}$ also has a well-established role in management of diabetic neuropathy, a role which is based on compiled studies and which has been proven to be a safe and effective practice. ${ }^{41}$

In vivo studies have shown that EPO provides endothelial protection, which is found to be mediated via activation of NOS, ${ }^{42}$ thus antagonizing the effects of ADMA. In addition, EPO is known to have both a direct and indirect antioxidative role through recruitment of iron in red blood cell production (thus depleting body iron) and by increasing the number of new erythrocytes which are loaded with antioxidants. ${ }^{43}$ The reduction in EPO doses noticed by the end of the present study in the ALA-treated group may have attenuated the beneficial effect on ADMA level and oxidative stress markers, and, as a result, inflammatory markers.

Patients in the present study were in general considered iron replete and did not show iron deficiency as revealed by their iron indices. ALA resulted in no effect on iron, ferritin, and TSAT\%. In general, patients were considered non-anemic, with few hemoglobin readings below $10.5 \mathrm{~g} / \mathrm{dL}$. ALA resulted in no effect on hemoglobin and hematocrit values; in contrast, it significantly reduced required EPO doses and ERI.

ERI response was not found to be related to age, sex, smoking status, time on dialysis, iPTH values, presence of $\mathrm{DM}$, presence of $\mathrm{HCV}$, and $\mathrm{Kt} / \mathrm{V}$; it was found to be related to only baseline ERI values. Analysis of covariance found no effect for all these covariates. These findings, however, should be expressed cautiously due to the small sample size.

One of the limitations of the present study is that it did not provide evidence of either the antioxidative or the anti-inflammatory effects of ALA; thus, the mechanism by which it improved anemia remains speculative. At first, it is worth noting that there is no evidence to support the use of a definitive biomarker, and a panel of different oxidative stress markers may be required to adequately assess the antioxidative effect of ALA. Trials investigating the antioxidants in hemodialysis patients have yielded contradictive outcomes. Moreover, the use of some antioxidants affected biomarkers differentially in the same study. For example, coenzyme $\mathrm{Q}_{10}$ suppressed advanced oxidation protein products, whereas it had no effect on MDA. ${ }^{44}$ Secondly, factors related to red blood cells have been suggested to contribute to the underlying mechanisms by which anemia occurs. The main erythrocyte metabolic pathway "hexosemonophosphate (HMP)" cycle and glucose-6phosphate dehydrogenase (G-6-PDH), a key enzyme of the HMP cycle, show decreased activity in patients undergoing regular hemodialysis. The HMP cycle plays a significant role in red blood cell antioxidant reactions because it is the only source of NADPH (reduced nicotinamide adenine dinucleotide phosphate). This compound is indispensable in the process of restoring reduced glutathione (GSH). The GSH system is one of the major scavengers of activated oxygen species in erythrocytes. Reduced antioxidant defense mechanisms in the erythrocyte leads to increased peroxidation of the polyunsaturated fatty acids (PUFA) in 
red blood cell membranes and increased susceptibility to damage, resulting in hemolysis and a reduction of erythrocyte life span. ${ }^{45,46}$ Hemodialysis patients have been found to have low levels of erythrocyte GSH, which is correlated to low G-6-PDH activities, ${ }^{47}$ and administration of exogenous glutathione to hemodialysis patients increased red blood cell GSH content, increased red blood cell survival, and reduced EPO need. This improvement was not accompanied by decreased oxidative stress indicator MDA. ${ }^{48}$ ALA is capable of regenerating other endogenous antioxidants such as GSH. Investigating erythrocyte G-6-PDH and GSH may provide the exact targets of ALA effects. This has been proven in diabetic rats, where ALA administration preserved the structural and functional integrity of red blood cells by increasing the red blood cell activities of antioxidant enzymes and of reduced GSH. ${ }^{49}$ Thirdly, the use of the nonspecific inflammatory marker HsCRP may yield positive results as found in a previous study. ${ }^{50}$ Lastly, one could not rule out the presence of other mechanisms mediating ALA lowering effect of EPO.

Some studies have reported lowered levels of anemia in hemodialysis patients with HCV when compared with no HCV. They found that HCV patients had better hemoglobin values and demanded less EPO doses than age-, gender- and race-matched $\mathrm{HCV}$-free patients. ${ }^{51,52}$ Bearing in mind that minor production of endogenous EPO comes from a healthy liver, ${ }^{53}$ it was hypothesized that the chronic inflammation as a result of $\mathrm{HCV}$ infection or regenerating liver cells cause increased circulation of EPO released from hepatocytes. $\mathrm{HCV}$ patients constituted a high proportion of the present study population, and hence may impact the outcome results (HCV has a high prevalence in the general population in Egypt, which is increased further in susceptible groups such as hemodialysis patients). If the previous observation applies, then these patients already have an inherently improved response to exogenous EPO, and any beneficial change, even mild and unnoticed (provided by the antioxidant effect of ALA), would have amplified responses. To examine such an assumption, an analysis for the subgroup of patients with no $\mathrm{HCV}$ was done. In the treated group, the reduction in EPO doses showed a trend toward significance and the reduction in ERI was significant; in contrast, in the control group both parameters showed insignificant changes. Although small, this subgroup revealed favorable outcomes that clearly confirmed the role of ALA in anemia management, in both $\mathrm{HCV}$-positive and HCV-negative hemodialysis patients. This was also demonstrated by the lack of effect HCV had on ERI results when analyzed as a covariate.

\section{Conclusion}

The study provided evidence for the use of ALA as an EPO adjuvant, reducing the requirement for EPO; this reduction not only offers economic advantages, it more importantly would protect against the proposed harmful effect of high EPO doses.

\section{Disclosure}

The authors report no conflicts of interest in this work.

\section{References}

1. Furuland H, Linde T, Ahlmén J, Christensson A, Strömbom U, Danielson BG. A randomized controlled trial of haemoglobin normalization with epoetin alfa in pre-dialysis and dialysis patients. Nephrol Dial Transplant. 2003;18(2):353-361.

2. Ayus JC, Go AS, Valderrabano F, et al; Spanish Group for the Study of the Anemia and Left Ventricular Hypertrophy in Pre-dialysis Patients. Effects of erythropoietin on left ventricular hypertrophy in adults with severe chronic renal failure and hemoglobin $<10 \mathrm{~g} / \mathrm{dL}$. Kidney Int. 2005;68(2):788-795.

3. Frank H, Heusser K, Höffken B, Huber P, Schmieder RE, Schobel HP. Effect of erythropoietin on cardiovascular prognosis parameters in hemodialysis patients. Kidney Int. 2004;66(2):832-840.

4. Robinson BM, Joffe MM, Berns JS, Pisoni RL, Port FK, Feldman HI. Anemia and mortality in hemodialysis patients: accounting for morbidity and treatment variables updated over time. Kidney Int. 2005;68(5): 2323-2330

5. KDOQI; National Kidney Foundation. KDOQI Clinical Practice Guidelines and Clinical Practice Recommendations for Anemia in Chronic Kidney Disease. Am J Kidney Dis. 2006;47(Suppl 3):S11-S145.

6. Locatelli F, Aljama P, Bárány P, et al; European Best Practice Guidelines Working Group. Revised European best practice guidelines for the management of anaemia in patients with chronic renal failure. Nephrol Dial Transplant. 2004;19 Suppl 2:ii1-i47.

7. Singh AK. What is causing the mortality in treating the anemia of chronic kidney disease: erythropoietin dose or hemoglobin level? Curr Opin Nephrol Hypertens. 2010;19(5):420-424.

8. Regidor DL, Kopple JD, Kovesdy CP, et al. Associations between changes in hemoglobin and administered erythropoiesis-stimulating agent and survival in hemodialysis patients. J Am Soc Nephrol. 2006; 17(4):1181-1191.

9. Hodkova M, Dusilova-Sulkova S, Kalousova M, et al. Influence of oral vitamin $\mathrm{E}$ therapy on micro-inflammation and cardiovascular disease markers in chronic hemodialysis patients. Ren Fail. 2006;28(5): 395-399.

10. Boaz M, Smetana S, Weinstein T, et al. Secondary prevention with antioxidants of cardiovascular disease in endstage renal disease (SPACE): randomised placebo-controlled trial. Lancet. 2000;356(9237): $1213-1218$.

11. Morimoto H, Nakao K, Fukuoka K, et al. Long-term use of vitamin E-coated polysulfone membrane reduces oxidative stress markers in haemodialysis patients. Nephrol Dial Transplant. 2005;20(12): 2775-2782.

12. Yang CC, Hsu SP, Wu MS, Hsu SM, Chien CT. Effects of vitamin C infusion and vitamin E-coated membrane on hemodialysis-induced oxidative stress. Kidney Int. 2006;69(4):706-714.

13. Chan D, Irish A, Dogra G. Efficacy and safety of oral versus intravenous ascorbic acid for anaemia in haemodialysis patients. Nephrology (Carlton). 2005;10(4):336-340.

14. Hsu SP, Chiang CK, Yang SY, Chien CT. N-acetylcysteine for the management of anemia and oxidative stress in hemodialysis patients. Nephron Clin Pract. 2010;116(3):c207-c216. 
15. Dashti-Khavidaki S, Khalili H, Barzegar E, et al. Effect of 4-week treatment with oral $\mathrm{N}$-acetylcysteine on plasma homocysteine concentration and antioxidant activity of patients on chronic hemodialysis. Kidney. 2008;17(3):122-125.

16. Kamgar M, Zaldivar F, Vaziri ND, Pahl MV. Antioxidant therapy does not ameliorate oxidative stress and inflammation in patients with end-stage renal disease. J Natl Med Assoc. 2009;101(4):336-344.

17. Tarng D-C. How can erythropoietin requirements be reduced in dialysis patients? Semin Dial. 2006;19(5):367-369.

18. Bjelakovic G, Nikolova D, Gluud LL, Simonetti RG, Gluud C. Mortality in randomized trials of antioxidant supplements for primary and secondary prevention: systematic review and meta-analysis. JAMA. 2007;297(8):842-857.

19. Huang KC, Yang CC, Hsu SP, et al. Electrolyzed-reduced water reduced hemodialysis-induced erythrocyte impairment in end-stage renal disease patients. Kidney Int. 2006;70(2):391-398.

20. Shay KP, Moreau RF, Smith EJ, Smith AR, Hagen TM. Alpha-lipoic acid as a dietary supplement: molecular mechanisms and therapeutic potential. Biochim Biophys Acta. 2009;1790(10):1149-1160.

21. [No author listed]. alpha-Lipoic acid. Altern Med Rev. 2006;11:232-237.

22. El-Beshbishy HA, Bahashwan SA, Aly HA, Fakher HA. Abrogation of cisplatin-induced nephrotoxicity in mice by alpha lipoic acid through ameliorating oxidative stress and enhancing gene expression of antioxidant enzymes. Eur J Pharmacol. 2011;668(1-2):278-284.

23. Sehirli O, Sener E, Cetinel S, Yüksel M, Gedik N, Sener G. Alpha-lipoic acid protects against renal ischaemia-reperfusion injury in rats. Clin Exp Pharmacol Physiol. 2008;35(3):249-255.

24. Kanter M, Sen S, Donmez S, Aktas C, Ustundag S, Erboga M. Protective effects of irbesartan and alpha lipoic acid in STZ-induced diabetic nephropathy in rats. Ren Fail. 2010;32(4):498-505.

25. Bhatti F, Mankhey RW, Asico L, Quinn MT, Welch WJ, Maric C. Mechanisms of antioxidant and pro-oxidant effects of alpha-lipoic acid in the diabetic and nondiabetic kidney. Kidney Int. 2005;67(4): 1371-1380.

26. Esterbauer H, Cheeseman KH. Determination of aldehydic lipid peroxidation products: malonaldehyde and 4-hydroxynonenal. Methods Enzymol. 1990;186:407-421.

27. López-Gómez JM, Portolés JM, Aljama P. Factors that condition the response to erythropoietin in patients on hemodialysis and their relation to mortality. Kidney Int Suppl. 2008:S75-S81.

28. Chang JW, Lee EK, Kim TH, et al. Effects of alpha-lipoic acid on the plasma levels of asymmetric dimethylarginine in diabetic end-stage renal disease patients on hemodialysis: a pilot study. Am J Nephrol. 2007;27(1):70-74.

29. Yilmaz A, Bekpinar S, Unlucerci Y, Gurdol F, Umman B. High concentrations of asymmetric dimethylarginine are associated with ST-segment resolution failure after reperfusion for acute myocardial infarction. Clin Chem Lab Med. 2011;49(5):903-907.

30. Wilson AM, Shin DS, Weatherby C, et al. Asymmetric dimethylarginine correlates with measures of disease severity, major adverse cardiovascular events and all-cause mortality in patients with peripheral arterial disease. Vasc Med. 2010;15(4):267-274.

31. Abedini S, Meinitzer A, Holme I, et al. Asymmetrical dimethylarginine is associated with renal and cardiovascular outcomes and all-cause mortality in renal transplant recipients. Kidney Int. 2010;77(1):44-50.

32. Zoccali C, Bode-Böger S, Mallamaci F, et al. Plasma concentration of asymmetric dimethylarginine and mortality in patients with end-stage renal disease: a prospective study. Lancet. 2001;358(9299):2113-2117.

33. Lee WJ, Kim SW, Kim SH, et al. Alpha-lipoic acid activates dimethylarginine dimethylaminohydrolase in cultured endothelial cells. Biochem Biophys Res Commun. 2010;398(4):653-658.

34. Mittermayer F, Pleiner J, Francesconi M, Wolzt M. Treatment with alpha-lipoic acid reduces asymmetric dimethylarginine in patients with type 2 diabetes mellitus. Transl Res. 2010;155(1):6-9.

35. Singh U, Jialal I. Alpha-lipoic acid supplementation and diabetes. Nutr Rev. 2008;66(11):646-657.
36. Veresiu IA. Intravenous alpha-lipoic acid improves fructosamine level in type 2 diabetes patients. Acta Endocrinol (Buc). 2009;5(4): 501-506.

37. Hong SB, Uhm WH, Joo WC, Nam MS, Lee SW, Song JH. Plasma markers of oxidative stress, inflammation and endothelial cell injury in diabetic patients with overt nephropathy administered alpha-lipoic acid and angiotensin II receptor blocker. Mol Cell Toxicol. 2010;6(2): $179-185$.

38. Xiang G, Pu J, Yue L, Hou J, Sun H. $\alpha$-lipoic acid can improve endothelial dysfunction in subjects with impaired fasting glucose. Metab Clin Exp. 2011;60(4):480-485.

39. Heinisch BB, Francesconi M, Mittermayer F, et al. Alpha-lipoic acid improves vascular endothelial function in patients with type 2 diabetes: a placebo-controlled randomized trial. Eur J Clin Invest. 2010;40(2) $148-154$.

40. Morcos M, Borcea V, Isermann B, et al. Effect of alpha-lipoic acid on the progression of endothelial cell damage and albuminuria in patients with diabetes mellitus: an exploratory study. Diabetes Res Clin Pract. 2001;52(3):175-183.

41. Ziegler D, Nowak H, Kempler P, Vargha P, Low PA. Treatment of symptomatic diabetic polyneuropathy with the antioxidant alpha-lipoic acid: a meta-analysis. Diabet Med. 2004;21(2):114-121.

42. d'Uscio LV, Smith LA, Santhanam AV, Richardson D, Nath KA, Katusic ZS. Essential role of endothelial nitric oxide synthase in vascular effects of erythropoietin. Hypertension. 2007;49(5):1142-1148.

43. Katavetin P, Tungsanga K, Eiam-Ong S, Nangaku M. Antioxidative effects of erythropoietin. Kidney Int Suppl. 2007:S10-S15.

44. Sakata T, Furuya R, Shimazu T, Odamaki M, Ohkawa S, Kumagai H. Coenzyme Q10 administration suppresses both oxidative and antioxidative markers in hemodialysis patients. Blood Purif. 2008;26(4): 371-378.

45. Stepniewska J, Dolegowska B, Ciechanowski K, Kwiatkowska E, Millo B, Chlubek D. Erythrocyte antioxidant defense system in patients with chronic renal failure according to the hemodialysis conditions. Arch Med Res. 2006;37(3):353-359.

46. Taccone-Galluci M, Lubrano R, Trapasso E, et al. Oxidative damage to RBC membranes and pentose phosphate shunt activity in hemodialysis patients after suspension of erythropoietin treatment. ASAIO J. 1994;40(3):M663-M666.

47. Paşaoğlu H, Muhtaroğlu S, Güneş M, Utaş C. The role of the oxidative state of glutathione and glutathione-related enzymes in anemia of hemodialysis patients. Clin Biochem. 1996;29(6):567-572.

48. Zachée P, Ferrant A, Daelemans R, Goossens W, Boogaerts MA, Lins RL. Reduced glutathione for the treatment of anemia during hemodialysis: a preliminary communication. Nephron. 1995;71(3): 343-349.

49. Mirjana M, Jelena A, Aleksandra U, et al. Alpha-lipoic acid preserves the structural and functional integrity of red blood cells by adjusting the redox disturbance and decreasing O-GlcNAc modifications of antioxidant enzymes and heat shock proteins in diabetic rats. Eur $J$ Nutr. 2012;51(8):975-986.

50. Khabbazi T, Mahdavi R, Safa J, Pour-Abdollahi P. Effects of alphalipoic acid supplementation on inflammation, oxidative stress, and serum lipid profile levels in patients with end-stage renal disease on hemodialysis. J Ren Nutr. 2012;22(2):244-250.

51. Khurana A, Nickel AE, Narayanan M, Foulks CJ. Effect of hepatitis C infection on anemia in hemodialysis patients. Hemodial Int. 2008; 12(1):94-99.

52. Lin YL, Lin CW, Lee CH, Lai IC, Chen HH, Chen TW. Chronic hepatitis ameliorates anaemia in haemodialysis patients. Nephrology (Carlton). 2008;13(4):289-293.

53. Weidemann A, Johnson RS. Nonrenal regulation of EPO synthesis. Kidney Int. 2009;75(7):682-688. 


\section{Publish your work in this journal}

The International Journal of Nephrology and Renovascular Disease is an international, peer-reviewed open-access journal focusing on the pathophysiology of the kidney and vascular supply. Epidemiology, screening, diagnosis, and treatment interventions are covered as well as basic science, biochemical and immunological studies. The journal welcomes

original research, clinical studies, reviews \& evaluations, expert opinion and commentary, case reports and extended reports. The manuscript management system is completely online and includes a very quick and fair peerreview system, which is all easy to use. Visit http://www.dovepress.com/ testimonials.php to read real quotes from published authors.

Submit your manuscript here: http://www.dovepress.com/international-journal-of-nephrology-and-renovascular-disease-journal 